\title{
UNA ALUMNA DE OFTALMOLOGÍA EN VALENCIA (1910)
}

\author{
LÓPEZ DE LETONA $C^{1}$
}

La verdad es que hasta bien entrado el siglo XX la nómina de las mujeres oculistas fue muy escasa pudiendo citarse sobre todo el nombre de Trinidad Arroyo y alguna más, pero curiosamente hemos encontrado el caso de una alumna de medicina en Valencia quien presentó un trabajo de nuestra especialidad que se hizo merecedor de un premio convocado por una revista oftalmológica.

Era María Luisa Quadras Bordes que publico el trabajo al que hacemos referencia en 1919. El lugar de aparición fue España oftalmológica, que se había fundado en Octubre de 1915 con el subtítulo de «Revista de clínica y terapéutica ocular», tenía carácter mensual y sus editores eran cuatro oftalmólogos conocidos: J. De Arana Quintana, de Sevi1la. Eduardo Wieden Viñarta, de Valencia, Fermín Muñoz Urra que vivía en Talavera de la Reina y finalmente el malagueño S. Díaz Rodríguez.

Era en esta ultima ciudad donde se imprimió la publicación, concretamente en la calle del Duque de la Victoria número 5.

La primera vez que se convocó el referido premio debió ser el año anterior y en su segunda convocatoria se le concedió a nuestra protagonista. El título del trabajo presentado era: Operación del ectropión cicatricial. Procedimieno empleado por el Dr. Tomas Blanco Bandebrande.

Comienza por afirmar que la corrección del ectropión cicatricial mediante la realización de un injerto dermo-epidémico en mosaico era una de las intervenciones menos practicada siendo sin embargo la que ofrecía mejores resultados.

Describe enseguida otras técnicas al uso como el método de Fricke en el cual se realizaba un deslizamiento de la piel de la región vecina que recubría la zona afectada. Pero no siempre daba buenos resultados, dependiendo éstos de que la zona sobre la que se implantara fuese pequeña.

Se refiere también a la técnica de P. Berger, que sólo cita de pasada, hablando eso sí de la colocación de un aparato y de «La educación al enfermo». Del mismo modo el procedimiento de Reverdin en la que se utilizan pequeñas porciones epidérmicas, pero sin llegar a ser el mosaico que describe más adelante.

Todos estos procederes citados hasta ahora tenían el inconveniente que con frecuencia se producían gangrenas, cayéndose enseguida la zona recién implantada y produciendo un daño mayor que el ya existente.

Por todo ello cita enseguida el procedimiento del injerto dérmico epidérmico en mosaico que había sido descrito ya por De Wecker unos años antes, pero que su maestro el Dr. Tomas Blanco Bandebrande usaba con éxito en Valencia.

Antes de entrar en la descripción del mismo hace referencia a que los demás métodos acaso fallasen porque se retiraba demasiado pronto la blenorrafia, es decir que una vez realizada la intervención era necesario suturar los párpados y dejarlos así al menos seis meses... evidentemente a día de hoy esto nos puede parecer un asunto cuanto menos curioso.

Desde 1891 Blanco, practicaba esta operación con éxito, la describe enseguida: Previa anestesia cutánea con cocaína muy diluida, media hora antes de intervenir, procede a lavar la zona afectada con agua boricada, después y con sumo cuidado disecciona la zona afectada del párpado, obteniendo una tirilla. No debe interesar al párpado en todo su espesor sino lo menos profundo posible.

Posteriormente diseca una zona en la cara interna del brazo, en forma de huso, procurando obtener solamente piel y lo menos posible de tejido celular subcutáneo. Después venía la parte más complicada de la operación, obtener pequeños fragmentos de la zona extirpada y con sumo cuidado irles disponiendo en la zona afectada por el ectropion en el párpado.

Si fuese posible se podrían fijar al párpado con pequeños hilos de plata, pero como esto resultada

\footnotetext{
1 IOBA. Valladolid. España.

E-mail: berta@ioba.med.uva.es
} 
casi siempre imposible los depositaban en las zonas afectadas cubriéndolos con una capa muy ligera de vaselina esterilizada.

Una vez realizada la sutura palpebral había que procurar que la zona intervenida quedara accesible a fin de poder ser curada posteriormente, esto era también muy difícil, no es partidaria de usar como material de cura «Los vendoletes» porque al retirarlos era frecuente llevarse también los trozos de piel injertados. Prefiere «Unas tirillas de protectriz» que debía ser un trozo de gutaprecha muy flexible.

Enseguida pasa a referir un caso práctico, se trataba de una mujer a la que habían ingresado por presentar un ectropión cicatricial inferior izquierdo secuente a una «Pústula maligna», se acompañaba de conjuntivitis catarral crónica.

Antes de intervenir se realizaron curas con Sulfato de zinc «Al medio por ciento» para sanar la con- juntivitis. Posteriormente se hicieron los injertos y se realizó la blenorrafia que se retiró en su momento.

El resultado debió ser bastante satisfactorio a juzgar por las cuatro fotografías que acompañan al trabajo, de modo que en la última de ellas el párpado inferior aparece totalmente reconstruido y sobre todo que podía cerrarse el ojo perfectamente, cosa que no siempre ocurría.

Nunca sabremos quien era en realidad María Luisa Quadras Bordes, no encontramos su nombre en ninguno de los diferentes repertorios bibliográficos que solemos manejar habitualmente. Sería un golpe de suerte que alguno de nuestros lectores tuviese alguna referencia de la misma.

Es probable que no ejerciese la Oftalmología si bien por entonces debía ser una discípula aventajada de Tomás Blanco. 